\title{
Magnitude of pre-diabetes among adult Nigerians with essential hypertension in a primary care clinic of a tertiary hospital in South-eastern, Nigeria
}

\author{
Gabriel Uche Pascal Iloh, "*, Ndubueze Richard Uchenna ${ }^{2}$ \\ ${ }^{1}$ Department of Family Medicine, Federal Medical Centre, Umuahia, Abia state, Nigeria \\ ${ }^{2}$ Department of Family Medicine, Federal Medical Centre, Owerri, Imo state, Nigeria
}

\section{Email address:}

ilohgup2009@yahoo.com (G. U. P. Iloh)

\section{To cite this article:}

Gabriel Uche Pascal Iloh, Ndubueze Richard Uchenna. Magnitude of Pre-Diabetes among Adult Nigerians with Essential Hypertension in a Primary Care Clinic of a Tertiary Hospital in South-Eastern, Nigeria. European Journal of Preventive Medicine. Vol. 2, No. 1, 2014, pp. 1-8. doi: 10.11648/j.ejpm.20140201.11

\begin{abstract}
Background: Hypertension co-existing with Diabetes mellitus is increasing globally. However, current evidence has demonstrated the existence of a prolonged, intermediate phase of diabetes termed pre-diabetes in hypertensive patients. Aim: This study was designed to determine the magnitude of pre-diabetes among adult Nigerians with essential hypertension in a primary care clinic of a tertiary hospital in South-eastern, Nigeria. Materials and Methods: A crosssectional analytic study carried out on 320 adult hypertensive Nigerians who were age and sex matched with 320 nonhypertensive, non-diabetic control group at the primary care clinic of a tertiary hospital in South-eastern Nigeria. These patients were screened for pre-diabetes. Pre-diabetes was defined as fasting plasma glucose of $100-125 \mathrm{mg} / \mathrm{dL}$ and /or plasma glucose level of 140-199 mg/dL two hours after a $75 \mathrm{~g}$ oral glucose load. Hypertension was defined as systolic and/or diastolic blood pressures $\geq 140 / 90 \mathrm{mmHg}$ or documented use of antihypertensive medications in a previously diagnosed person with hypertension. Results: The prevalence of pre-diabetes was significantly higher in hypertensive patients $(33.1 \%)$ than control $(16.2 \%)(\mathrm{p}=0.001)$ with impaired fasting glycaemia $((29.4 \%)$ being the more common pattern. The mean fasting plasma glucose of the hypertensive patients $(122.4 \mathrm{mg} / \mathrm{dL} \pm 1.7)$ ) was significantly higher than that of the control $(91.8 \mathrm{mg} / \mathrm{dL} \pm 2.4)(\mathrm{p}=0.000)$. Similarly, the mean two hours oral glucose load of the hypertensive patients $(183.4 \mathrm{mg} / \mathrm{dL} \pm 1.6)$ was significantly higher than that of the control $(161.8 \mathrm{mg} / \mathrm{dL} \pm 1.9)(\mathrm{p}=0.001)$. Conclusion: This study has shown the existence of pre-diabetes among the hypertensive patients with impaired fasting glycaemia being the more common pattern. Screening adult Nigerians with essential hypertension for pre-diabetes should constitute clinical targets for intervention in primary care clinic.
\end{abstract}

Keywords: Adult Hypertension, Nigeria, Pre-Diabetes, Primary Care Clinic

\section{Introduction}

Hypertension and Diabetes mellitus have received the greatest global attention in the last two decades.[1,2] Both conditions are the most common cause of morbidity and mortality from non-communicable diseases in Africa.[3] The number of people living with Diabetes mellitus currently is 240 million globally and over 7 million in Africa.[1] These populations are about a quarter and a third of the corresponding number of hypertensive patients in Africa, and the world respectively.[1]

Hypertension is an important public health issue and has been described as a "silent killer" that often times has no detectable symptoms while causing continuous and progressive damage to the target organs of the body.[4,5] Similarly, Diabetes mellitus is increasing globally and in its natural history has an intermediate, often symptomless phase known as pre-diabetes(PD) characterized by impaired fasting glucose (IFG) and impaired glucose tolerance (IGT).[6] Hypertension may co-exist with the intermediate phase of Diabetes mellitus (pre-diabetes) probably because they share similar constitutional and nonconstitutional risk factors.[7,8] Pre-diabetes increases the risk of Diabetes mellitus in hypertensive patients and both undiagnosed pre-diabetes and Diabetes mellitus are associated with diabetic complications.[9,10] The association of pre-diabetes and hypertension increase the 
overall cardiovascular risk for the patients with the comorbid clinical conditions.

Pre-diabetes is a medical condition in which the blood glucose level is higher than the normal value but not high enough to meet the criteria for the diagnosis of Diabetes mellitus.[11] It is characterized by fasting plasma glucose $100-125 \mathrm{mg} / \mathrm{dL}$ and/or plasma glucose level $140-199$ $\mathrm{mg} / \mathrm{dL}$ two hours after a $75 \mathrm{~g}$ oral glucose load. [6] These conditions are known as impaired fasting glucose (IFG) and impaired glucose tolerance (IGT) respectively. Although individuals with impaired fasting glucose and/or impaired glucose tolerance do not meet criteria for Diabetes mellitus, they are at substantial risk for developing Diabetes mellitus and cardiovascular diseases.[10,12,13]

As the prevalence of Diabetes mellitus increases worldwide, $[1,13]$ so will the prevalence of pre-diabetes increase since the latter is a phase in the natural history of Diabetes mellitus.[6,7] In United States of America, a prevalence of pre-diabetes of $25 \%$ was reported in US adults and only $4 \%$ of them were aware of the medical condition.[14] In another study in United States of America, Shobha et al,[15] reported prevalence of $9.7 \%$ for impaired fasting glucose and $15.6 \%$ for impaired glucose tolerance in their study of US adults aged $40-74$ years while Lorna et al,[16] reported a prevalence of impaired fasting glucose of $23.5 \%$ among New York City adults. In Canada, a prevalence of pre-diabetes of $3.5 \%$ was reported among primary care patients.[13] Shuqian et al,[17] in a study on the prevalence of diabetes mellitus and IFG in Chinese adults found an IFG prevalence of $4.9 \%$. Shrestha et al,[18] reported a prevalence of $43 \%$ among hypertensive patients in urban Nepal. In Nigeria, a prevalence of $25 \%$ was reported among hypertensive patients in a teaching hospital in Enugu, Nigeria. [7]

Screening high risk adult hypertensive patients specifically for pre-diabetes is a primary care clinic imperative as persons with pre-diabetes are at increased risk for the development of cardiovascular complications independent of progression to Diabetes mellitus[19-21] Management of pre-diabetes with dietary modifications, exercise and weight reduction could attenuate progression to Diabetes mellitus,[21-23] hence the benefit of early detection of diabetes mellitus at pre-diabetic stage cannot be overemphasized. This type of study has not been carried out in the study area thus there is a knowledge gap regarding pre-diabetes and its burden among adult hypertensive patients in primary care setting. The findings of this study would help to bridge this gap and also provide data for the clinical condition of pre-diabetes among hypertensive Nigerians in primary care clinic. It is therefore pertinent to detect early the addition of prediabetes in adult Nigerians with essential hypertension as early intervention may alter cardiovascular endpoints. The researchers therefore sought to study the magnitude (prevalence and pattern) of pre-diabetes among adult Nigerians with essential hypertension in a primary care clinic of a tertiary hospital in South-eastern, Nigeria.

\section{Materials and Methods}

\subsection{Ethical Approval}

Ethical certificate was obtained from the Ethics Committee of the hospital. Informed consent was also obtained from patients included in the study.

\subsection{Study Design}

This was a primary care clinic-based cross-sectional analytic study carried out from February 2011 to June 2011. A total of 320 consecutive adult patients with essential hypertension and 320 non-diabetic and non-hypertensive control were screened for pre-diabetes at the department of Family Medicine of Federal Medical Centre, Owerri, a tertiary hospital in Imo State, South-eastern, Nigeria.

\subsection{Study Setting}

Owerri is the capital of Imo State, South-east Nigeria. The State is endowed with abundant mineral and agricultural resources with supply of professional, skilled, semi-skilled and unskilled manpower. Economic and social activities are low compared to industrial and commercial cities such as Onitsha, Port Harcourt and Lagos in Nigeria. Until recently, the capital city and its environ have witnessed an upsurge in the number of banks, hotels, schools, markets, industries, junk food restaurants in addition to the changing dietary and social lifestyles.

Federal Medical Centre, Owerri is located in the municipal city of Owerri. It is a tertiary hospital established with the tripartite mandate of service delivery, training and research and serves as a referral centre for primary and secondary public health institutions as well as missionary and private hospitals in Imo State and neighbouring States of Abia, Ebonyi, Rivers and Akwa Ibom States of Nigeria.

The department of Family Medicine serves as a primary care clinic within the tertiary hospital setting of the Medical Centre. All adult patients excluding those who need emergency health care services, paediatric patients and antenatal women are first seen at the department of Family Medicine where diagnoses are made. Patients who need primary care are managed and followed up in the clinic while those who need other specialists care are referred to the respective core specialist clinics for further management. The clinic is run by consultant Family Physicians and postgraduate resident doctors in Family Medicine.

\subsection{Study Population}

The study population was made up of 320 adult hypertensive patients who presented to the primary care clinic of the hospital during the study period and met the inclusion criteria. This category of patients constituted the cases. The control population was also selected from the primary care clinic of the hospital and was made up of 320 non-hypertensive and non-diabetic patients. 
The control group was matched for age and sex. The matching for the age was based on age group matching as in the case category. The control population was subjected to the same screening test for pre-diabetes. The cases and control were studied simultaneously during the period

\subsection{Inclusion and Exclusion Criteria for the Cases}

The inclusion criteria were patients with essential hypertension aged $\geq 18$ years who gave informed consent for the study. The exclusion criteria included pregnant patients, diabetic and critically ill patients.

\subsection{Sample Size Determination}

The sample size for the study was determined from the sample size formula for comparing proportions in the two groups[24] $\mathrm{N}=\left[\mathrm{Z} \alpha \sqrt{ }\left(2 \mathrm{P}_{1}\left(1-\mathrm{P}_{1}\right)+\mathrm{Z}(1-\beta) \sqrt{\mathrm{P} 1}\left(1-\mathrm{P}_{1}\right)+\mathrm{P}_{2}(1-\right.\right.$ $\left.\left.\mathrm{P}_{2}\right)\right]^{2} /\left[\mathrm{P}_{1}-\mathrm{P}_{2}\right]^{2}$, Where $\mathrm{N}=$ the minimum sample size, $\alpha=0.05$, $\beta=0.80, Z \alpha=1.96, Z(1-\beta)=0.842, P_{1}=$ the prevalence of prediabetes of $25 \%$ in hypertensive patients reported in a previous study in Enugu, Nigeria.[7] and $\mathrm{P}_{2}=$ prevalence of pre-diabetes in the control group from previous study in Enugu $=3 \%$. This gave a minimum sample estimate of 52 hypertensive patients and 52 control group. A total of 320 adult hypertensive patients and 320 control groups were recruited from those who presented to the clinic during the study period and met the inclusion criteria.

\subsection{Sampling Technique}

Sample selection was done consecutively based on the inclusion criteria for the hypertensive cases. The control group was selected simultaneously based on those that met the matching criteria with the cases.

\subsection{Basic Demographic Data}

The basic demographic data collected from the study population included age, sex, marital status, education and occupation. The social classification of patients was based on five points occupational scale used by Abramson.[25] However, this was re-classified into lower, middle and upper occupational classes to suit Nigerian environment. Class I and II belong to upper class, class III belongs to middle class while class IV and V belong to lower class.

\subsection{Diagnostic Procedures}

The blood pressure was measured using auscultatory method with standard mercury in glass Accuson sphygmomanometer. Prior to the measurement, the patient was seated and rested for 5 minutes [26] in sitting position on a chair that supported the back comfortably. The left arm muscles were relaxed and the forearm was supported with the cubital fossa at the heart level. A cuff of suitable size was applied evenly to the exposed arm. The cuff was rapidly inflated until the manometer reading was about $30 \mathrm{mmHg}$ above the level at which the pulse disappeared and then slowly deflected. During this time, the Korotkoff sounds were monitored using a Litman stethoscope placed over the brachial artery. The systolic blood pressure was noted at the pressure at which the first heart sounds were heard(Korotkoff phase I). The diastolic blood pressure was taken as the pressure at the point when the heart sounds disappeared(Korotkoff phase v). The blood pressure was also measured in the right arm as described for the left arm in order to rule out significant inter-arm blood pressure difference and the arm that gave the higher reading was subsequently used. [26] The systolic and diastolic blood pressures were measured twice separated by an interval of 2 minutes. [26] The three readings were recorded and the mean value was calculated.

The blood glucose was determined after an overnight fast between 8.00 hours to 10.00 hours. After adequate disinfection of the skin over the venepuncture site, 2 millilitres of venous blood sample was drawn from the cases and control group for fasting glucose estimation. The cases and control were thereafter given $75 \mathrm{~g}$ anhydrous glucose dissolved in $250 \mathrm{mls}$ of water to drink over 5 minutes. Two millilitres of venous blood sample was collected in the same manner two hours after the glucose load. The plasma glucose estimations were determined by the glucose oxidase method.[11]

\subsection{Diagnostic Criteria}

The fasting blood glucose results were grouped as normal fasting blood glucose $(60-99 \mathrm{mg} / \mathrm{dL})$, impaired fasting glucose $(100-125 \mathrm{mg} / \mathrm{dL})$ and diabetes mellitus $(\geq$ $126 \mathrm{mg} / \mathrm{dL})$. The two hours oral glucose tolerance test was classified as $60-139 \mathrm{mg} / \mathrm{dL}$ (normal), $140-199 \mathrm{mg} / \mathrm{dL}$ (impaired glucose tolerance) and $\geq 200 \mathrm{mg} / \mathrm{dL}$ diabetes mellitus).

\subsection{Operational Definitions}

Hypertension was defined as systolic and/or diastolic blood pressures $\geq 140 / 90 \mathrm{mmHg}$ or documented use of antihypertensive medications in a previously diagnosed person with hypertension.[27] Pre-diabetes was defined as fasting plasma glucose of $100-125 \mathrm{mg} / \mathrm{dL}$ and /or plasma glucose level of $140-199 \mathrm{mg} / \mathrm{dL} 2$ hours after a $75 \mathrm{~g}$ oral glucose load.[6] Diagnosis of Diabetes mellitus was based on venous plasma glucose of $\geq 126 \mathrm{mg} / \mathrm{dl}$ after an overnight fast which was confirmed by a repeat test on second clinic visit.[27] Primary care refers to the care provided by physicians specifically trained for comprehensive first contact and continuing care for undifferentiated patients including early detection, management of the patient, health promotion and maintenance.

\subsection{Statistics}

The results generated were analyzed using software Statistical Package for Social Sciences (SPSS) version 13.0, Microsoft Corporation Inc. Chicago, IL, USA for the calculation of percentages for categorical variables and 
mean for continuous data. Categorical variables were compared by Chi-square test while the mean of fasting blood glucose and oral blood glucose load between the two groups were done by the independent t-test. A p-value of $<$ 0.05 was considered statistically significant.

\section{Results}

The age of the hypertensive patients ranged from 18 years to 79 years with a mean age of $52 \pm 11.82$ years while the age of the control group ranged from 18 years to 79 years with mean age of $52 \pm 12.72$ years. There were 105 males $(32.8 \%)$ and 215 females $(67.2 \%)$ in both the hypertensive patients and the control with a male to female ratio of 1: 2.1. Other demographic characteristics of the hypertensive cases and their control group are shown in table 1.

Table 1. Demographic characteristics of the study population

\begin{tabular}{|c|c|c|}
\hline Variable & Hypertension group Number (\%) & Control group Number (\%) \\
\hline \multicolumn{3}{|l|}{ Age } \\
\hline$<30$ & $4(1.3)$ & $4(1.3)$ \\
\hline $30-39$ & $50(15.6)$ & $50(15.6)$ \\
\hline $40-49$ & $94(29.4)$ & $94(29.4)$ \\
\hline $50-59$ & 101(31.6) & 101(31.6) \\
\hline $60-69$ & $50(15.6)$ & $50(15.6)$ \\
\hline$\geq 70$ & $21(6.5)$ & $21(6.5)$ \\
\hline Total & $320(100.0)$ & $320(100.0)$ \\
\hline \multicolumn{3}{|l|}{ Sex } \\
\hline Male & $105(32.8)$ & $105(32.8)$ \\
\hline Female & $215(67.2)$ & $215(67.2)$ \\
\hline \multicolumn{3}{|l|}{ Marital status } \\
\hline Married & $222(69.0)$ & 293(92.0) \\
\hline Single & $23(7.0)$ & $23(7.0)$ \\
\hline Widowed & $67(21.0)$ & $0(0.0)$ \\
\hline Separated & $8(3.0)$ & $4(1.0)$ \\
\hline Total & $320(100.0)$ & $320(100.0)$ \\
\hline \multicolumn{3}{|l|}{ Education } \\
\hline No formal education & $29(9.1)$ & $14(4.4)$ \\
\hline Primary & 121(37.8) & $97(30.3)$ \\
\hline Secondary & $81(25.3)$ & $80(25.0)$ \\
\hline Tertiary & $89(27.8)$ & $129(40.3)$ \\
\hline Total & $320(100.0)$ & $320(100.0)$ \\
\hline \multicolumn{3}{|l|}{ Occupation } \\
\hline Student/unemployed & $24(7.5)$ & $2(0.6)$ \\
\hline Trading & $105(32.8)$ & $92(28.8)$ \\
\hline Farming & $44(13.8)$ & $79(24.7)$ \\
\hline Artisans & $21(6.6)$ & $32(10.0)$ \\
\hline Civil servants & $126(39.3)$ & $115(35.9)$ \\
\hline Total & $320(100.0)$ & $320(100.0)$ \\
\hline \multicolumn{3}{|l|}{ Social class } \\
\hline Lower & $137(42.8)$ & $113(35.3)$ \\
\hline Middle & $123(38.4)$ & $127(39.7)$ \\
\hline Upper & $60(18.8)$ & $80(25.0)$ \\
\hline Total & $320(100.0)$ & $320(100.0)$ \\
\hline
\end{tabular}


Table 2. Prevalence of pre-diabetes among the study population

\begin{tabular}{|c|c|c|c|c|c|c|}
\hline Pre-diabetes & Hypertension group Number (\%) & Control group Number (\%) & $x^{2}$ & df & P-value & Remark \\
\hline Yes & $106(33.1)$ & $52(16.2)$ & & & & \\
\hline No & $214(66.9)$ & $268(83.8)$ & & & & \\
\hline Total & $320(100.0)$ & $320(100.0)$ & 24.5 & 1 & .001 & Significant \\
\hline
\end{tabular}

Table 3. Pattern of pre-diabetes among the study population

\begin{tabular}{lcc}
\hline Pre-diabetes & Hypertension group Number (\%) & Control group Number (\%) \\
\hline Impaired fasting glucose & $94(88.7)$ & $46(88.5)$ \\
Impaired glucose tolerance & $12(11.3)$ & $6(11.5)$ \\
Total & $106(100.0)$ & $52(100.0)$ \\
\hline
\end{tabular}

Table 4. Mean fasting blood glucose and 2 hours glucose load among the study population.

\begin{tabular}{lccccc}
\hline Parameter & Hypertension group Mean(SD)mg/dL & Control group Mean(SD)mg/dL & t-test & P-value & Remark \\
\hline Fasting blood glucose & $122.4(1.7)$ & $91.8(2.4)$ & 1.88 & $<.001$ & Significant \\
2 hours glucose load & $183.4(1.6)$ & $161.8(1.9)$ & 1.02 & .001 & Significant \\
\hline
\end{tabular}

One hundred and six out of a total of 320 hypertensive patients had pre-diabetes giving a prevalence of $33.1 \%$. Of the 320 subjects in the control group, 52 had pre-diabetes giving a prevalence of $16.2 \%$ for the control group. The difference between the two groups was statistically significant $\left(\chi^{2}=24.5, \mathrm{df}=1, \mathrm{p}=.001\right)$. [Table 2]

Out of the 106 hypertensive subjects with pre-diabetes, ninety four $(88.7 \%)$ had impaired fasting glucose while twelve $(11.3 \%)$ had impaired glucose tolerance. Of the total prevalence of $33.1 \%$ among the hypertensive patients, impaired fasting glucose constituted a prevalence of $29.4 \%$ while impaired glucose tolerance was $3.7 \%$. In the control group, forty-six $(88.5 \%)$ out of the 52 control group with pre-diabetes had impaired fasting glucose while six (11.5\%) had impaired glucose tolerance. This translates to a prevalence of $14.3 \%$ for impaired fasting glucose and $1.9 \%$ for impaired glucose tolerance out of the total prevalence of $16.2 \%$ among the control group. [Table 3]

Table 4 shows the mean fasting blood glucose and two hours oral glucose load of the hypertensive patients and the control group. The mean fasting blood glucose and two hours oral glucose load between the two groups was statistically significant. $(\mathrm{t}=1.88, \mathrm{p}$-value $=<.001 ; \mathrm{t}=1.02, \mathrm{p}$ value $=.001)$. [Table 4]

\section{Discussion}

The prevalence of pre-diabetes among the study population was $33.1 \%$. This is higher than $25 \%$ reported among hypertensive patients in Enugu, Nigeria[7] and 3.5\% reported among primary care patients in Canada. [13] The prevalence of pre-diabetes in this study is lower than $39.1 \%$ reported in Calabar, Nigeria[28] and 43\% reported in Nepal.[18] However, the prevalence of pre-diabetes of $33.1 \%$ in this study is within the range of $25.0 \%-47.0 \%$ reported in the European Study of Hypertension and Diabetes.[29] However, this study has demonstrated the existence of pre-diabetes in essential hypertension which is an issue of phenomenal clinical and public health importance in Nigeria.[7,28] and other parts of the world such as Taiwan where pre-diabetes is a rapidly emerging epidemic.[30] This study has buttressed the previous reports that the prevalence of pre-diabetes in essential hypertension in Nigeria is relatively low but is rapidly changing. [7,28] Although pre-diabetes is an intermediate phase in the natural history of type 2 diabetes mellitus but pre-diabetic patients are at increased risk of progressing to type 2 diabetes mellitus and developing cardiovascular complications of diabetes mellitus.[10,31] However, not all hypertensive patients with pre-diabetes will progress to type 2 diabetes mellitus, but their chances of developing type 2 diabetes mellitus are high.[8,9,10] This may be promoted and enhanced by mutable cardiovascular risk factors such as diet, physical inactivity and immutable risk factors like age, sex and ethnicity.[31,32] The finding of this study therefore portends a possible increase in the incidence of type 2 diabetes mellitus among adult Nigerians with essential hypertension and underscores the need to critically assess these patients during clinical encounter in primary care setting for pre-diabetes. This will help to reduce the health costs associated with management of their hypertensive condition and possible concurrent type 2 diabetes mellitus.

The impaired fasting glycaemia was the more common pattern of pre-diabetes among the study population. However, the finding of this study has informed the need for baseline clinical evaluation for impaired fasting glycaemia and impaired glucose tolerance at the diagnosis of essential hypertension in primary care. Screening for pre-diabetes as an additional risk factor among adult Nigerians with essential hypertension will provide physicians with an important opportunity to improve on the clinical care of hypertensive patients. This ensures optimal health for adult Nigerians with essential hypertension who 
are at risk of developing dysmetabolic syndrome characterized by abnormal glucose homeostasis. Studies have also shown that pre-diabetes share similar cardiometabolic risk factors with diabetes mellitus and thus confers some degree of cardiovascular risk among adult Nigerians with essential hypertension and its concurrent health hazards. This study has therefore buttressed the documentation of the growing evidence of the association between hypertension and pre-diabetes. Early detection of pre-diabetes in adult hypertensive patients and subsequent effective intervention will beneficially alter the course of the disease and thus improve hypertensive management outcome.[9]

This study has shown that the hypertensive patients had a significantly higher mean fasting blood glucose and oral glucose load than the control group respectively. This finding is similar to previous reports in Nigeria.[7,28] and other parts of the world such as Nepal.[18] Although, the exact physiological mechanism linking pre-diabetes with essential hypertension are not known, but available evidence suggest that both conditions are related through insulin resistance in glucose metabolism and hyperinsulinaemia.[6,29] This is also explained in the constellation of abnormalities linking type 2 diabetes mellitus, hypertension and others constellations of metabolic syndrome.[8,32] Pre-diabetes induce changes in the cardiovascular system leading to cardiovascular diseases and it has been shown to be most pathologically relevant in the aetiopathogenesis of type 2 diabetes mellitus.[32] The strategies to reduce the risk and burden of type 2 diabetes mellitus in adult Nigerians with essential hypertension should therefore focus on control of prediabetes which is largely modifiable.[23] The earlier in the pre-morbid phase that pre-diabetes is detected in adult hypertensive patients, the better the prognosis and outcome of its management. [11-13] Establishing a baseline for the blood glucose and checking them during patients visits appropriately can provide the clinicians with an excellent means of educating their hypertensive patients on lifestyle modifications and other diverse clinical care.

\subsection{Implications of the Study}

Disease patterns have been changing in recent decades in Nigeria due to socio-economic development and demographic changes. Non-communicable diseases such as hypertension and diabetes mellitus are implicated for rising morbidity and mortality from cardiovascular diseases in Nigeria and carry great concern for the future.[5,27] Hypertensive individuals do not just develop diabetes mellitus overnight, they go through a prolonged intermediate phase termed pre-diabetes which at present has been recognized as a phase in the natural history of diabetes mellitus.[6] Pre-diabetes increases the risk of cardiovascular diseases and both undiagnosed diabetes mellitus and pre-diabetes are associated with diabetic complications since they share similar risk factors.[33,34] In view of this, screening for pre-diabetes specifically in the high risk groups such as adult patients with essential hypertension needs further attention especially in primary care settings in Nigeria. The health providers, managers and policy makers should direct interventional strategies to control hypertension and pre-diabetes as envisioned in the WHO global strategy on diet, physical activity and health. [33-38]

\subsection{Limitations of the Study}

The authors had certain constraints which imposed some degree of limitations to the absolute generalization of the findings: The limitations imposed by the cross sectional 'case-control' nature of the study design are recognized by the researchers. Hypertension may antedate the development of pre-diabetes and vice versa. However, this study stimulates the need for longitudinal studies. This would enable a quasi cause-effect relationship to be drawn and also for a reliable and valid conclusion to be ascertained.

The sample size used was comparatively small, but this was the number of patients seen during the approved duration of the study. The sample was drawn from hospital attendees in the study area as only patients who presented to the clinic were studied. Thus extrapolation and generalization of the results of the study to the entire population should be done with utmost caution because the findings may not be a true representation of what may be obtained in the community.

The study didn't exclude hypertensive patients that were on anti-hypertensive medications that affect glucose homeostasis such as $\beta$-blockers and thiazide diuretics among other lifestyle factors that affect glucose metabolism. However, reports in Nigeria showed that antihypertensive medications that affect glucose metabolism didn't significantly affect the prevalence of pre-diabetes among hypertensive Nigerians.[28]

More so, the limitations of not matching the hypertensive patients for body mass index and other socio-demographic characteristics such as occupation, marital status, education and socio-economic class among others are recognized by the authors. This was designed to avoid over-matching on the patients socio-demographic characteristics which might lead to variable degree of systematic error.

Furthermore, the authors didn't measure insulin levels because of absence of facilities for it in the study centre. However, hyperinsulinaemia and insulin resistance are not found in every patient with hypertension and not all patients with hyperinsulinaemia have hypertension.

\section{Conclusion}

This study has shown the existence of pre-diabetes among the hypertensive patients with impaired fasting glycaemia being the more common pattern. Screening adult hypertensive Nigerians for pre-diabetes should constitute clinical targets for intervention in primary care clinic. 


\section{Future Research Direction}

In the study area, further hospital-based and communitybased studies are recommended in order to further explore risk factors of pre-diabetes and its correlates. This will provide valuable clinical and epidemiological data for collaborative purposes.

\section{References}

[1] Wild S, Roglic G, Green A, Sicree R, King H. Global prevalence of Diabetes. Estimates for the year 2000 and projections for 2030. Diabetes Care 2004; 27:1047-1053.

[2] Kearney PM, Whelton M, Reynolds K. Global burden of hypertension- analysis of worldwide data. Lancet 2005; 365: 217-223.

[3] Unwin N, Setel P, Rashid S, Mugusi F, Mbanya JC, Kitange $\mathrm{H}$, et al. Non-communicable diseases in sub-Saharan Africa: where do they feature in the health research agenda? Bull World Health Organ 2001; 79: 947-953.

[4] Familoni OB. Hypertension-how much do our patients know? Africa Health 2002; 24: 13.

[5] Ayodele OE, Alebiosu CO, Salako BL, Awoden OG, Adigun A. Target organ damage and associated clinical conditions among Nigerians with treated hypertension. Cardiovasc J South Afr 2005; 16: 89-93.

[6] Ramlo-Halsted BA, Edelman SV. The natural history of type 2 diabetes: Implications for clinical practice. Prim Care 1999; 26: 771-789

[7] Ogbu I. S, Neboh C. I. The prevalence of Prediabetes among hypertensive patients in Enugu, Southeast Nigeria. Niger Med J 2009: 50: 14-17.

[8] Shyam SG, Mohammed AA, Kamlesh B, Kalyan KD. Prevalence of pre-hypertension and associated cardiovascular risk profiles among prediabetic Omani adults. BMC Public Health 2008; 8: 108.

[9] Tuomilehto J, Lindstron J, Eriksson JG, Valla TT, Hamalainen H, Illane-Parikka P et al. Prevention of type 2 DM by changes in lifestyle among subjects with impaired glucose tolerance. N Engl J Med 2001; 344: 1343-1350.

[10] Robinson SJ, Gordon SA, Russell JW, Feldman EL. Microvascular complications of impaired glucose tolerance. Diabetes 2003; 52: 2867-2873.

[11] Iloh GUP, Uchenna NR, Obiegbu NP. Risk factors of prediabetes among adult Nigerians with essential hypertension in a resource-constrained setting of a primary care clinic in eastern Nigeria. American Journal of Health Research 2013; 1: $56-64$.

[12] Harris MI, Eastman RC. Early detection of undiagnosed Diabetes mellitus: a US perspective. Diabetes Metab Res Rev 2000; 16: 230-236.

[13] Leiter L.A., Barr A., Belanger A, Labin S, Ross A, Tidesley H D. et al, Diabetes screening in Canada, (DIASCAN), study. Prevalence of undiagnosed diabetes and glucose intolerance in family physician offices. Diabetes Care 2001; 24: $1038-1043$
[14] Rolka DR, Burrows NR, Li Y, Geiss LS. Self-reported prediabetes and risk-reduction activities-US-2006. JAMA 2009; 301: 591-593.

[15] Shobha SR, Philips S, Tamara M. Impaired glucose tolerance and impaired fasting glucose. Am Fam Physician 2004; 69: 1961-1968, 1971-1972.

[16] Lorna ET, Ushma DU, Shadi C, Renu G, Diana KB, Charon $\mathrm{G}$ et al. Prevalence and control of diabetes and impaired fasting glucose in New York City. Diabetes Care 2009; 32: $57-62$.

[17] Shuqian L, Wenyu W, Xiaoguang Y, Elisa T, Jian Z, Yuna H et al. Prevalence of diabetes and impaired fasting glucose in Chinese adults, China National Nutrition and Health survey 2002. Prev Chronic Dis 2011; 8(1).

[18] Shrestha UK, Singh DL, Bhattarai MD. The prevalence of hypertension and diabetes defined by fasting and 2 hour plasma glucose criteria in urban Nepal. Diabetes Medicine 2006; 23: 1130-1135.

[19] Kuller LH, Veletgas P, Barzilay J, Beauchamp NJ, 'O' leary DH, Savage PJ. Diabetes mellitus: subclinical cardiovascular disease and risk of incident mortality. Arterioscer Thromb Vasc Biol 2000; 20: 823-829.

[20] The DECODE study: Group for the European Diabetes Epidemiology. Glucose tolerance and cardiovascular mortality: comparison of fasting and two hour diagnostic criteria. Arch Intern Med 2001; 161: 397-405.

[21] Cynthia C, Harvey K, Bonita E, Falkner BE. The utility of fasting glucose for detection of prediabetes. Metabolism 2006; 55: 434-438.

[22] Gerstein H, Yusuf S, Bosch J, Pogue J, Sheridan P, Dinccag $\mathrm{N}$, et al "Effect of rosigiltazone on the frequency of diabetes in patients with impaired glucose tolerance or impaired fasting glucose: a randomized controlled trial". Lancet 2006 ; 368: 1096-1105.

[23] Riddell M, Fowles J. How to treat prediabetes with exercise effectively. Clinical practice guide Diabetes 2010; 10-20.

[24] Dawson B, Trapp RG. Basic and Clinical Biostatistics, $4^{\text {th }}$ edition, New York: Lange Medical Books \& McGraw-Hill 2004; p 145-146.

[25] Iloh GUP, Amadi AN, Nwankwo BO. Obesity in adult Nigerians: a study of its prevalence and common primary co-morbidities in a semi-urban Mission General Hospital in South-Eastern Nigeria. Niger J Med 2010; 19: 459-466.

[26] Onwubere B, Kadiri S. Guidelines for the management of hypertension in Nigeria. Nigerian Hypertension Society. Enugu, Ezu Books Limited 2005.p. 1-40

[27] Iloh GUP, Amadi AN, Nwankwo BO, Ugwu VC. Obesity in adult Nigerians: A study of its pattern and common primary co-morbidities in a rural Mission General Hospital in Imo state, south-eastern Nigeria. Niger J Clin Pract 2011; 14: 212-8.

[28] Essien OE, Peters EJ, Udoh AE, Ekott JU, Odigwe CO. Prevalence and pattern of abnormal glucose tolerance in adult Nigerians with primary hypertension. Niger J Med 2007; 16: 50-56

[29] Govindarajan G, Sowers JR, Stump C. Hypertension and 
Gabriel Uche Pascal Iloh and Ndubueze Richard Uchenna: Magnitude of Pre-Diabetes among Adult Nigerians with Essential Hypertension in a Primary Care Clinic of a Tertiary Hospital in South-Eastern, Nigeria

Diabetes Mellitus. European Cardiology 2006; 2: 1-7.

[30] Chen K, High L. Prevalence of impaired fasting glucose and type 2 diabetes mellitus in Penghu Islets, Taiwan: evidence of a rapidly emerging epidemic. Diab Res Clin Pract 2009; 44: 59-69.

[31] Mills JD, Grant PJ. Insulin resistance homeostasis factors and cardiovascular risk. Br J Diabetes Vasc Dis 2000; 2: 1926.

[32] Akintude AA. Epidemiological and conventional cardiovascular risk factors among hypertensive subjects with normal and impaired fasting glucose. S Afr Med J 2010; 100: 594-597.

[33] Iloh GUP, Ikwudinma AO Abdominal obesity in adult Nigerian Africans: prevalence and co- occurrence with cardio-metabolic risk factors in a resource poor setting of a rural hospital in Eastern Nigeria. American Journal of Health Research 2013; 1: 73-80.

[34] Azuamah YC, Amadi AN, Amadi COA, Esenwah EC, Azuamah EC, Iloh GUP. Co-occurrence of diabetes mellitus and hypertension in some rural communities of southeast
Nigeria. International Journal of Advanced Medical Sciences and Applied Research 2011, 11: 30-41.

[35] WHO. Global strategy on diet, physical activity and health. Bulletins of the WHO 2006; 5: 16-8.

[36] Iloh GUP, Amadi AN, Ikwudinma AO, Njoku PU. Prevalence and family biosocial predictors of abdominal obesity among adult Nigerian Africans in a resource constrained setting of a rural hospital in Eastern Nigeria. European Journal of Preventive Medicine 2013; 1: 70 -78.

[37] Iloh GUP, Chuku A, Obiegbu NP, Ofoedu JN, Ikwudinma AO. Frequency of cardiovascular risk factors in adult Nigerians with family history of non-communicable cardiovascular disease in a primary care clinic of a tertiary hospital in a resource-constrained environment of Eastern Nigeria. American Journal of Health Research 2013; 1: 1725.

[38] Iloh GUP, Ikwudinma AO, Obiegbu NP. Obesity and Its Cardio-metabolic Co-morbidities Among Adult Nigerians in a Primary Care Clinic of a Tertiary Hospital in SouthEastern Nigeria. J Fam Med Primary Care 2013; 2: 20-26. 